\title{
Perspectivas recientes sobre las conductas de rechazo a la escolarización
}

\author{
Benjamin Witts, Daniel Houlihan
}

Minnesota State University;

Mankato, Minnesota

EE.UU.

benjamin.witts@gmail.com 


\section{Resumen}

Se llevó a cabo una revisión de la literatura sobre el rechazo de la escolarización. Se descubrió que el término Conductas de Rechazo a la Escolarización ha pasado por muchos cambios. Estos cambios incluyen nomenclatura, etiología y tratamiento.

Los nombres que se han usado para describir la conducta de rechazo escolar van desde el absentismo escolar (truancy) en los años 1930, hasta las conductas de rechazo a la escolarización en los años 1990. Otros términos han sido aplicados y todavía se aplican hoy, por ejemplo la Fobia Social.

Actualmente, lo que más se usa es una definición funcional del rechazo a la escolarización, y ésta corresponde directamente a los tratamientos recomendados que dependen de la función que representa el rechazo.

Palabras Clave: conductas de rechazo a la escolarización, absentismo escolar, intervención, fobia escolar, fobia social.

Recepción del artículo: $\quad$ 27-03-2007

Aceptación provisional: $\quad$ 12-05-2007

Aceptación definitiva: $\quad$ 05-06-2007 